\title{
Multitemporal High-Resolution Satellite Images for the Study and Monitoring of an Ancient Mesopotamian City and its Surrounding Landscape: The Case of Ur
}

\author{
Giacomo Di Giacomo and Giuseppe Scardozzi \\ Istituto per i Beni Archeologici e Monumentali (IBAM), Consiglio Nazionale delle Ricerche (CNR), \\ Strada per Monteroni c/o Campus Universitario, 73100 Lecce, Italy \\ Correspondence should be addressed to Giuseppe Scardozzi, g.scardozzi@ibam.cnr.it
}

Received 7 February 2012; Revised 9 June 2012; Accepted 24 June 2012

Academic Editor: Nicola Masini

Copyright (C 2012 G. Di Giacomo and G. Scardozzi. This is an open access article distributed under the Creative Commons Attribution License, which permits unrestricted use, distribution, and reproduction in any medium, provided the original work is properly cited.

\begin{abstract}
The paper concerns the use of multitemporal high-resolution satellite images for the study of the ancient city of Ur, in southern Mesopotamia, inaccessible to scholars from 2003. The acquired dataset is composed by two Gambit KH-7 (1966) and one Corona KH-4B (1968) declassified spy space photos and by few images taken by the recent satellites for civilian use QuickBird-2 (2002, 2004, 2007), Ikonos-2 (2008), and WorldView-1 (2008). The processing of all these images and the integration with ASTER and SRTM DEMs allowed the acquisition of new data about the topographical layout of the city and its monuments and ancient roads; the georeferencing of all archaeological remains and traces visible on the images allowed the upgrade of the archaeological map of Ur. The research also provided important data concerning the reconstruction of the surrounding landscape, where a lot of traces of old channels and riverbeds of the Euphrates were identified in areas much modified and altered during the last decades by urbanization and agricultural works. Moreover, the multitemporal images allowed the monitoring of the conservation of the archaeological area, particularly before and after second Gulf War.
\end{abstract}

\section{Introduction}

The research activity concerning Ur was gained in the context of the "Virtual Museum of Iraq" Project, promoted by the Italian Ministry of Foreign Affairs and carried out by the National Research Council (CNR) of Italy. The project was designed to the construction of a Virtual Museum of the ancient civilizations that flourished in the territory of modern Iraq; the result was a rich website (http://www.virtualmuseumiraq.cnr.it/), free to the general public, based on the archaeological collection of one of the most important museums in the world. In fact, in 2003, during the 2nd Gulf War, the National Museum of Baghdad has been looted, stripping it of a priceless collection of cultural artefacts that are important historical treasures not only for Iraqi people but also for all humanity. The "Virtual Museum of Iraq" Project explored different new integrated digital technologies for virtual heritage, particularly focusing on the use of image-based 3D modelling and satellite remote sensed data [1-7]. Specifically, the present work concerns the case of the ancient city of Ur, in southern Mesopotamia (Figure 1), that is exemplificative of the contribution of high-resolution satellite images for the reconstruction of the ancient topography and the monitoring of the site.

\section{Methodology: The Research Activity concerning Ur in the "Virtual Museum of Iraq" Project}

In the "Virtual Museumof Iraq" Project, the activities of the Institute for Archaeological and Monumental Heritage (IBAM-CNR) were focused on the realization of 3D reconstruction of settlements, monuments, and objects of the most important archaeological Iraqi sites and on the contextualization of finds stored into the Baghdad Museum, 


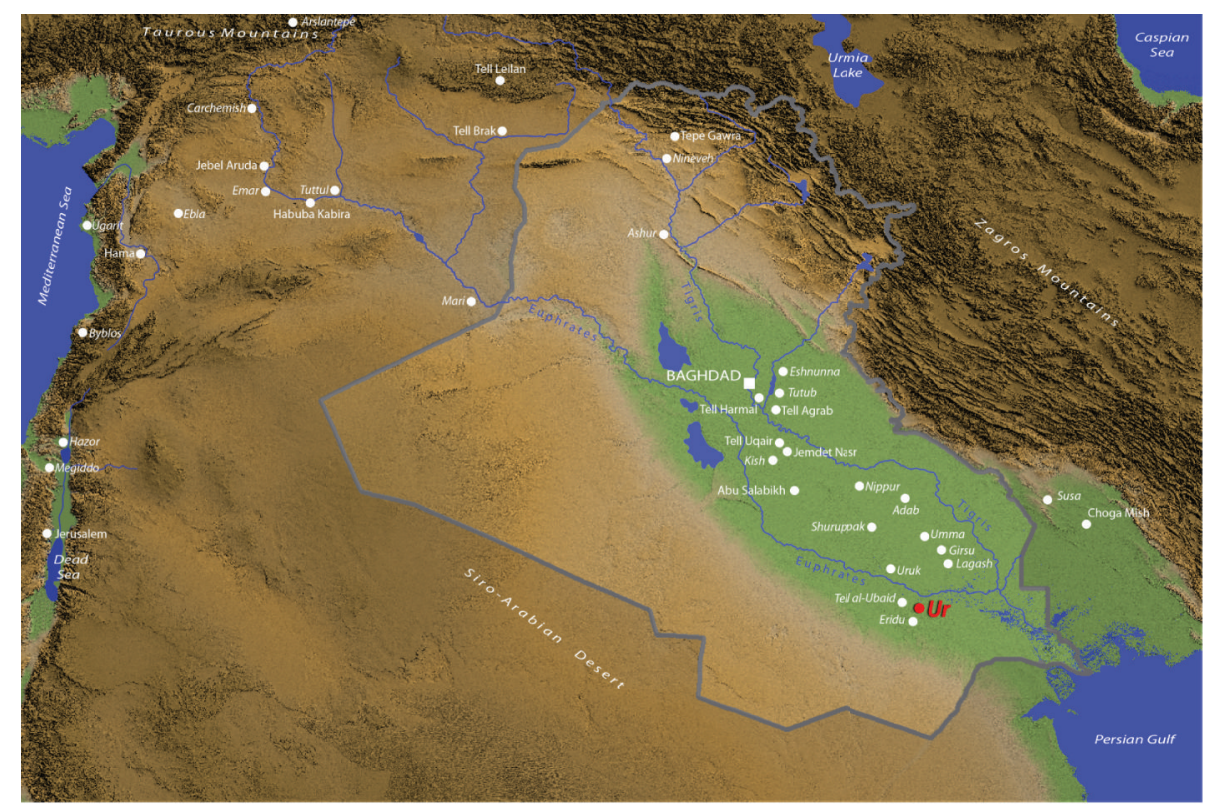

FIgURE 1: Ur in the southern Mesopotamia (Digital Elevation Model processed from the Shuttle Radar Topography Mission).

linking them to their sites of provenance. This process of contextualization enables the "visitors" of the Virtual Museum to view the original territorial contexts of the finds and it was implemented on three temporal levels: the ancient times, the moment of the discovery, and modern times. The virtual reconstructions, including those based on excavation photos, yield excellent results for the first two levels. Concerning the third temporal level, allowing a virtual visit to the place of provenance in its current situation, the photographic images, both aerial and from the ground, allow the user to view the archaeological areas with a very high detail. Considerable problems arise, however, in situations where the contexts are not easily accessible and adequate photographic documentation is not available. This is the case of much ancient cities and settlements of Iraq; generally, only few terrestrial images and some oblique aerial photographs of small sectors of the archaeological areas are available, together with some documents (graphic and photographic) of the excavations. An important contribution to the resolution of this problem, as well as to the recovery of documentation that serves to complement any photographic material that may be available, has been provided by highresolution satellite images.

For each chronological section of the Virtual Museum, two or three archaeological sites more representative were chosen; they were documented by cataloguing the most significant monuments in order to provide the "visitors" of the Virtual Museum with a complete image of the characteristics of the contexts where the artefacts were found. In particular, the ancient city of Ur was chosen both for the Sumerian and the Neo-Babylonian "Halls" of the Museum.

In the section "Archaeological Sites" of the Iraq Virtual Museum, the contribution of high-resolution multitemporal satellite images was very important. First of all, the images were used to document the modern situation of ancient sites and for monitoring their conditions before and after the first and second Gulf War. These images make it possible to observe and document the archaeological areas as they are today, both as a substitute for a real visit (currently impossible) and in preparation for a future visit. The detailed examination of these images also constitutes an important opportunity to acquire new data about the topographical layout of the sites and their principal monuments $[8,9]$. Moreover, satellite orthoimages were used for the production of new archaeological map of the ancient sites investigated in the research project [10].

In the case of Ur, we have a rich data set, starting from three panchromatic photos taken in the 1960s by the United States reconnaissance satellites Gambit KH-7 (1966; one vertical and one oblique, with a ground geometric resolution of $0.6 \mathrm{~m}$ ) and Corona KH-4B (1968; ground geometric resolution of about $1.83 \mathrm{~m}$ ). The documentation of the USA spy satellites covers the entire site and its surroundings; it is a fundamental tool for archaeological research, very useful when old aerial photos are scarce. In fact, thanks to their high geometric resolution, they allow the examination in detail of ancient urban areas and territories that later are changed or also partially destroyed; so, it is possible to detect and examine ancient structures, paleoenvironmental elements, and archaeological traces of buried features not yet visible [11].

The satellite documentation of the 1960s was augmented by the use of five high-resolution images taken between 2002 and 2008 by the commercial satellites QuickBird-2 (2002, 2004, 2007; Standard Ortho-ready products), Ikonos-2 (2008; Carterra Geo Ortho kit product), and WorldView-1 (2008; Standard Ortho-ready product). These images constitute an up-to-date documentation, very useful for the study and presentation of the archaeological site, through which it is possible also to compare with the aerial photos taken by 


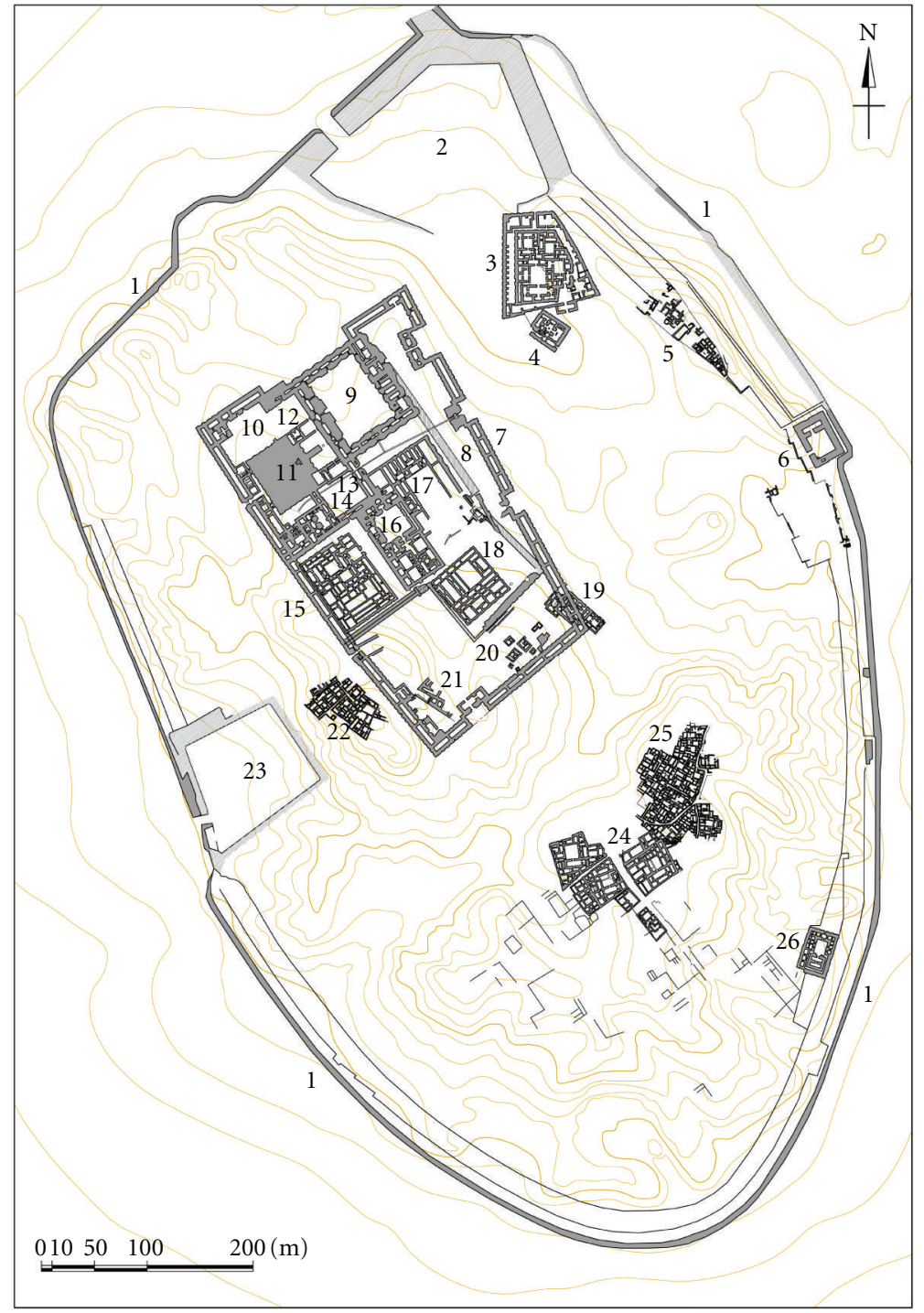

Figure 2: The new general plan of Ur (drawn up by F. Ghio): 1: City Wall; 2: North Harbour; 3: Palace of Ennigaldi-Nanna; 4: Harbour Temple; 5: Houses on City Wall; 6: Kassite Fort; 7: enclosure of the Sacred Area in the neo-Babylonian period; 8: enclosure of the Sacred Area during the 3rd Dynasty; 9: Nanna Court; 10: Etemenniguru; 11: Ziggurat; 12: Nanna Temple; 13: Boat Shrine; 14: Ningal Temple; 15: Giparku; 16: Edublamakh; 17: Ganunmakh; 18: Ekhursag; 19: Mausolea of the 3rd Dynasty; 20: Royal Graves; 21: Nimintabba Temple; 22: Houses (EM District); 23: West Harbour; 24: Houses (AH District); 25: neo-Babylonian Houses; 26: Enki Temple.

Royal Air Force pilots during the main excavations of Ur in 1930s. The high geometric, spectral, and radiometric resolutions of the recent satellite images allowed the detailed analysis of the archaeological site; particularly, their very high ground geometric resolution (between 1 and $0.5 \mathrm{~m}$ in panchromatic mode; between 4 and $2.40 \mathrm{~m}$ in multispectral mode) makes them similar, in terms of definition, to vertical aerial photographs on a middle scale that in the case of Ur are scarce. The images made it possible to obtain a detailed view from above of the current state of the ancient remains and their layouts, given the possibility of noticing even quite small details; they enabled us to identify elements that are not easily perceptible on the ground and to recognize the traces of structures that are still buried or have become buried again since their original excavation. Moreover, it is also possible to identify some paleoenvironmental features [12-18].

Very useful in the study of the site was also the integration of the images with ASTER and SRTM DEMs, from which were also extracted the contour lines of the new archaeological map of Ur elaborated during the research (Figure 2). The 3D models of the terrain show the tell of Ur, composed from successive stratifications, that rises approximately $20 \mathrm{~m}$ above the surrounding plain. The DEMs also allowed the $3 \mathrm{D}$ visualization of the site and its surroundings, and they made it possible to associate the archaeological traces and anomalies to the morphology of the ground thanks to the draping of the satellite images on the models (see Figure 7). 


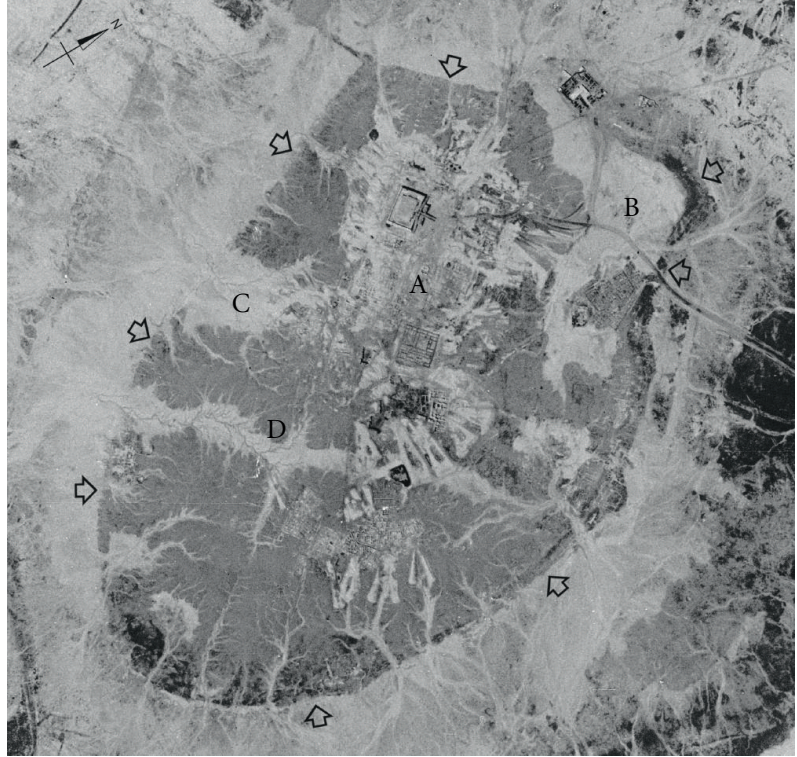

(a)

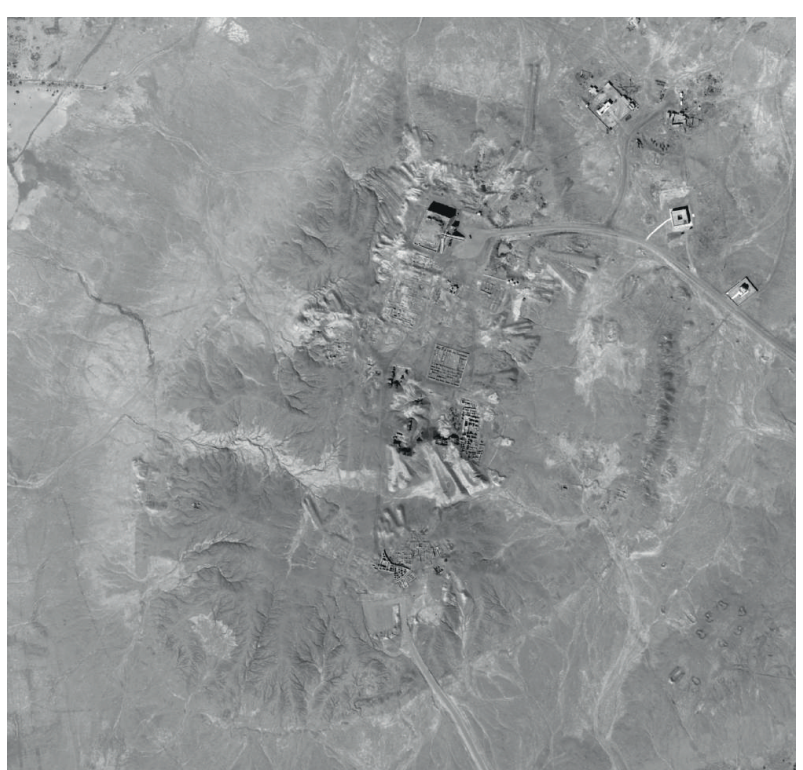

(b)

Figure 3: The hill of Ur in a Gambit KH-7 photograph taken in April 1966 and in a WorldView-1 image acquired in March 2008: A: the sacred area with the Ziggurat and the other main monuments; B: the North Harbour; C: the West Harbour, a depression that probably corresponds to an ancient channel. The arrows indicate traces and remains of the city walls.

\section{Data Set}

The data set used in this research is very detailed and covers a time span ranging from 1966 to 2008. Technical developments in the fields of electronics, optics, and space engineering of the last 50 years have made a substantial contribution to the study of the archaeological site of Ur, allowing multitemporal analysis, using historical images taken by spy satellites during the 1960s, and then multispectral investigation, thanks to the images of modern satellites for civilian use.

The oldest images coming from the historical archives of the USGS (United States Geological Servicehttp://www.usgs.gov/) provide datasets of declassified images from spy satellites constellation Corona and Gambit. The Corona program was the first United States strategic reconnaissance satellites project operated by the Central Intelligence Agency in cooperation with US Air Force. The Corona satellites were originally used for photographic surveillance of the Soviet Union (USSR) and of China, but during the operational phase satellites acquired images of many other areas of the world. The Corona program began in June 1959 and ended in May 1972. Satellite series were designated $\mathrm{KH}-1, \mathrm{KH}-2, \mathrm{KH}-3, \mathrm{KH}-4, \mathrm{KH}-4 \mathrm{~A}$, and $\mathrm{KH}-4 \mathrm{~B}$; $\mathrm{KH}$ is an acronym for "Key Hole" and the incrementing number indicates changes in the instrumentation (e.g., the camera type). 144 Corona satellites were launched and 102 of them returned usable photographs.

The altitude of these satellites was 165 to 460 kilometers above the surface of the Earth, so the cameras could acquire images with a ground resolution down to 7.5 meters; satellites used special 70 millimeter film with 60 -centimeters focal length cameras. The two $\mathrm{KH}-4 \mathrm{~A}$ and $\mathrm{KH}-4 \mathrm{~B}$ systems improved this resolution to $2.75 \mathrm{~m}$ and $1.8 \mathrm{~m}$, respectively, because they operated at lower orbital altitudes. The KH-4 satellites used two panoramic cameras with 30-degree separation angle to produce stereoscopic imagery; in particular, the $\mathrm{KH}-4 \mathrm{~B}$ system used two convergent rotating panoramic (black and white) cameras to record dual images of specific areas on the Earth with ground resolution of about $1.83 \mathrm{~m}$ and focal length of 60 centimetres and a Dual Improved Stellar Index Camera for target location identification and assistance in mapping. During 16 successful missions (from September 1967 to May 1972) it has produced 188,000 frames: an image taken on May 4, 1968, was used for this work, but this is not the oldest image available.

In fact, the dataset also includes two images taken in 1966 from a satellite of Gambit KH-7 series. The KH-7 was the first satellite for high-quality reconnaissance images. The system was designed to work with Corona program to take higher resolution images of a smaller area and the operational phase started in July 1963 and ended in June 1967. Gambit KH-7 successfully returned film on 34 of 38 missions and the usable images came from 30 missions. Satellites returned a total of 19,000 frames, with an initial ground resolution of $1.2 \mathrm{~m}$; by 1966 , best resolution improved to $0.6 \mathrm{~m}$. These satellites, equipped with a Kodak advanced lens drive scanning Optical Bar camera system with its forward rotating primary mirror and folding optics capable of creating images on large format on a 9 inch wide, provided key cartographic information for large-scale (1:50,000) maps for US Department of Defense; priority targets for systems included Soviet and Chinese nuclear installations, but photos of other areas were taken. Most of the imagery from the KH-7 satellites was declassified 


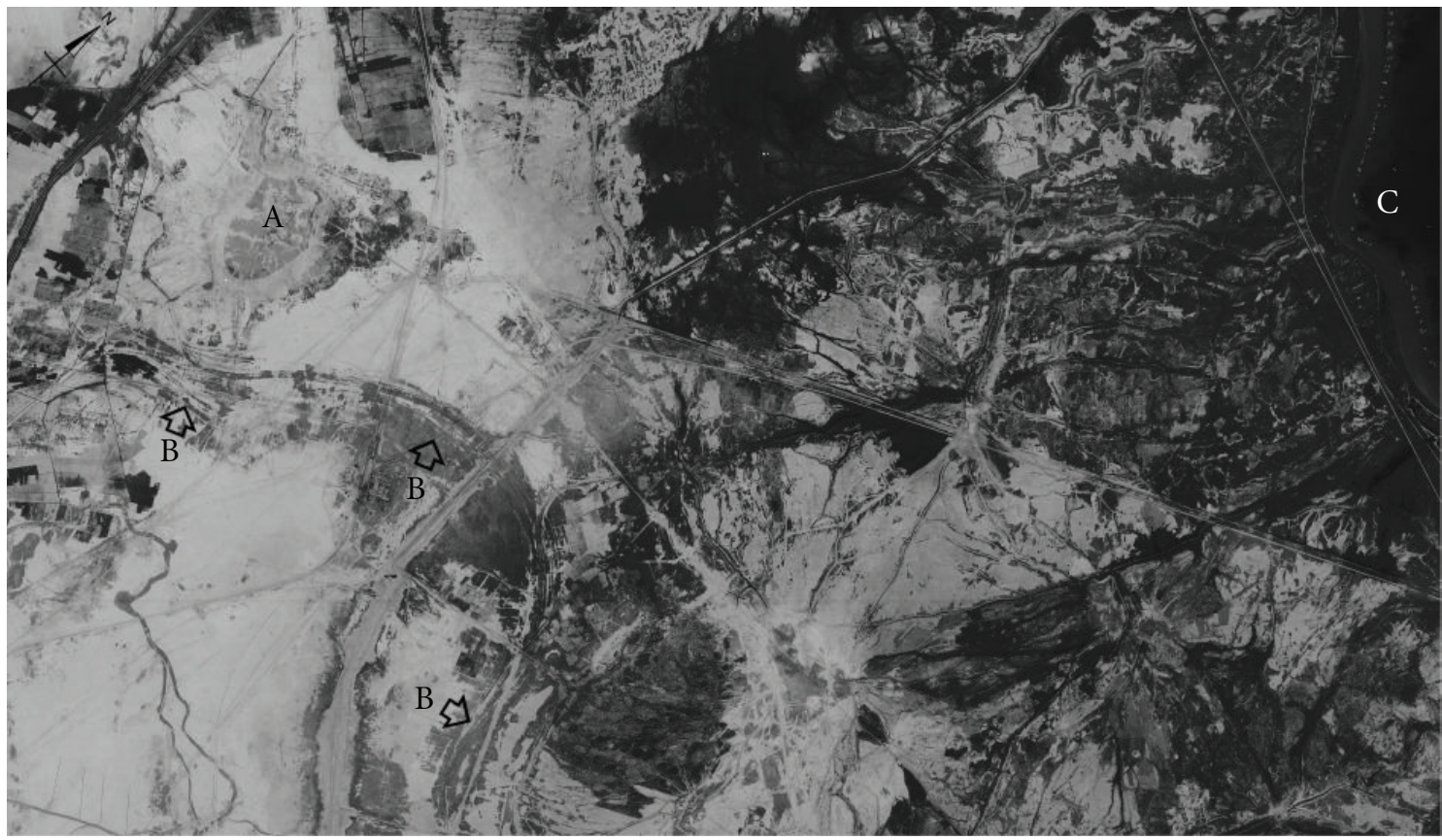

FIgURE 4: The territory of Ur (A) in a Gambit KH-7 photograph taken in April 1966: the traces of a paleoriver bed of the Euphrates (B) and the present river bed $(\mathrm{C})$ are visible.

in 2002, and one oblique taken in February 18, 1966 and one vertical taken in April 23, 1966 (Figures 3 and 4; see also Figure 9) are part of the data set used for the research concerning Ur. In particular, the vertical image, as all the images acquired at nadir on the later $\mathrm{KH}-7$ missions, can be compared favourably with the best commercial systems like Ikonos-2, QuickBird-2, and WorldView-1.

Ikonos-2 is a commercial earth observation satellite, owned by GeoEye, and was the first to collect publicly available high-resolution imagery at $1 \mathrm{~m}$ in panchromatic mode and $4 \mathrm{~m}$ in multispectral mode (http://www.geoeye.com/). Ikonos-2 was launched in 2001 and imagery began being sold on January 1, 2000. Ikonos-2 is the first next-generation commercial satellite, capable of acquiring images in stereomode, by rotating the camera along track; this satellite uses telemetry to transfer data to the ground and to receive navigation data from remote control center. The system, based on a fully digital image acquisition, has a primary mirror aperture of $0.7 \mathrm{~m}$ and a folded optical focal length of $10 \mathrm{~m}$ using 5 mirrors. The detectors at the focal plane include a panchromatic and a multispectral sensor, with 13500 pixels and 3375 pixels, respectively (cross-track). The sensor collects data with a 11-bit (0-2047) sensitivity that are delivered in an unsigned 16-bit (0-65535) data format. Sometimes data are rescaled down to 8 bit (0-255) to decrease file size, but this causes a loss of data. Ikonos-2 revisit time is 3 to 5 days for off-nadir and 144 days for truenadir. An image taken by Ikonos-2 on August 9, 2008 was used for this work.

QuickBird-2 is another high-resolution commercial earth observation satellite, owned by DigitalGlobe and launched in 2001 (http://www.digitalglobe.com/). Until 2007 it has been the platform that has taken Earth images with the best geometric resolution; in fact the system collects 61centimeter class panchromatic and 2.5-meter multispectral data over a large field of view with rapid target selection. QuickBird-2 was equipped with a sensor implemented by Ball Aerospace and Technologies Corporation, named Ball Global Imaging System 2000 (BGIS 2000), designed to be an agile, stable, and highly accurate Earth remote sensing platform. The imaging system returns 11-bit digital high resolution imagery from space, with 23 meters of horizontal accuracy. The operational orbit of the satellite is set to an altitude of $450 \mathrm{~km}$ with 98 degree sun synchronous inclination. Revisit frequency is 1 to 3.5 days depending on latitude. In the research concerning Ur three Quickbird-2 images were used; they were taken on February 27, 2002, on April 04, 2004, and on March 20, 2007.

WorldView-1, another satellite of DigitalGlobe company, was successfully launched on September 18, 2007. It was equipped with only a panchromatic imaging system, which can acquire half-meter resolution imagery with a dynamic range of 11 bit per pixel. Operating at an altitude of 496 kilometers, WorldView-1 has an average revisit time of 1.7 days and is capable of collecting up to 750,000 square kilometers per day of half-meter imagery. The satellite is also equipped with state-of-the-art geolocation capabilities and exhibits stunning agility with rapid targeting and efficient in-track stereo collection. Only one image, captured by this satellite on March 10, 2008, was used for the case study concerning Ur (Figure 3).

These eight images taken over 40 years from different satellites, with different characteristics and in different seasons, make up the data set that was used for this case study. 


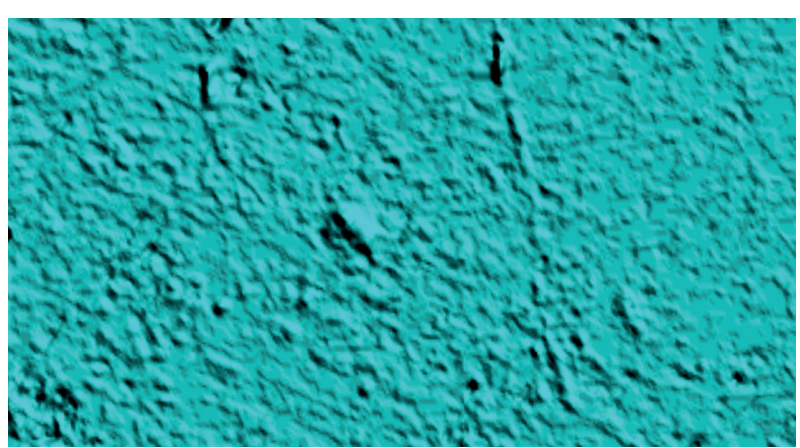

(a)

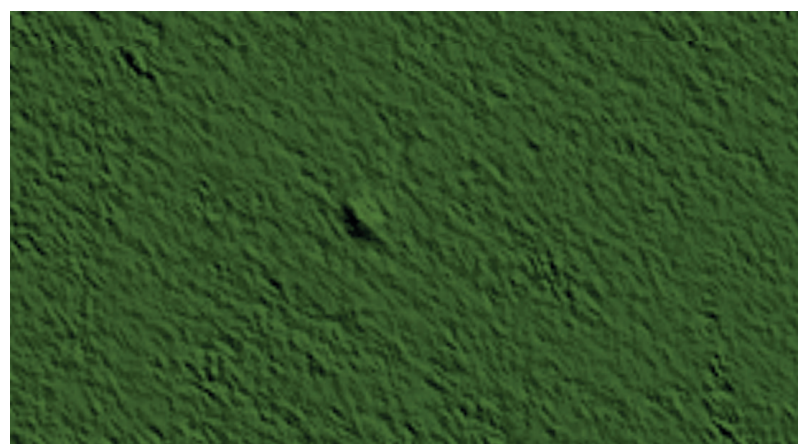

(b)

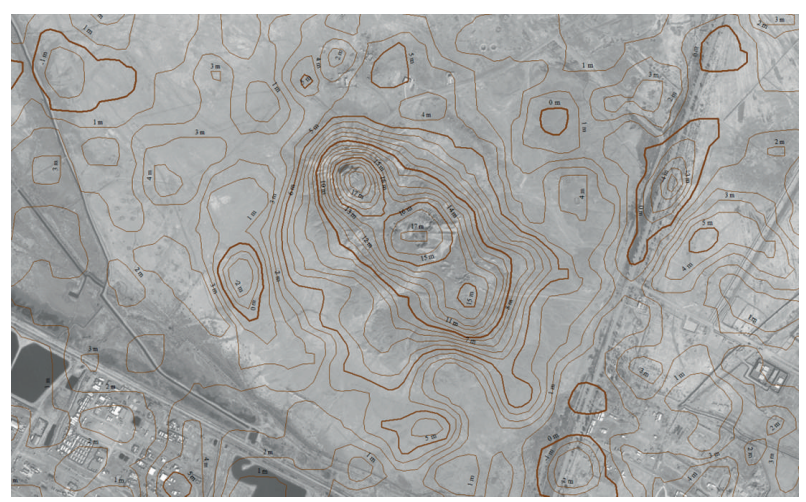

(c)

FIgure 5: The hill of Ur in ASTER (a) and SRTM (b) DEMs; contour lines (c) extracted from the SRTM DEM, draped with the QuickBird-2 panchromatic image of 2004.

Depending on the type of the image, it was possible to perform various analyses and processing, from georeferencing, reading, and interpretation of the older images to the application of algorithms for postprocessing of the digital images taken by modern satellites.

\section{Data Processing}

In this case study, and also during all activities of the "Virtual Museum of Iraq" Project, the analysis of satellite images represented an opportunity to acquire new data on the ancient topography of the archaeological sites that were examined. This documentation was very important specifically for contexts that have been studied many years ago or that are characterized by a history of the research centered mainly on individual complexes, monuments, or wealth of finds. In addition, these studies have often not interested the general layout of the settlement. However, is important to specify that in the analysis of remote sensing data verification on the ground of presences, traces, and anomalies is fundamental; it is in order to clarify their real pertinence to archaeological elements, their interpretation and, if possible, also their dating, avoiding misunderstandings and mistakes. But in the study cases of the project, the ground control with a survey of the sites was impossible, so we could often formulate only hypotheses and the only comparison was with published studies.

The preliminary data processing has been the developing of three-dimensional models of the area of Ur (Figure 5), starting from the radar data taken by the Shuttle Radar Topography Mission and from an optical stereo pair taken by the radiometer ASTER (Advanced Spaceborne Thermal Emission and Reflection) of the Terra satellite; this stereo pair was already processed by the data center of Land Processes (LP) of Distributed Active Archive Centers (DAAC), which is a part of NASA's Earth Observing System Data and Information System (EOSDIS).

The Shuttle Radar Topography Mission (SRTM) obtained elevation data on a near-global scale to generate the most complete high-resolution digital topographic database of Earth. SRTM consisted of a specially modified radar system that flew onboard the Space Shuttle during an 11-day mission in February of 2000. SRTM is an international project spearheaded by the National Geospatial-Intelligence Agency (NGA) and NASA. The processing method of SRTM data is divided in three stages: the first processing stage involves importing and merging the 1-degree tiles into continuous elevational surfaces in ArcGRID format. The second process fills small holes iteratively and the cleaning of the surface to reduce pits and peaks. The third stage then interpolates through the holes using a range of methods. The method used is based on the size of the hole and the landform that surrounds it. In the processing Arc/Info AML model was used. The final product is a shape file that contains three-dimensional data of Earth surface that can be used as a Digital Elevation Model to extract contours.

Instead the ASTER Digital Elevation Model product is generated using bands $3 \mathrm{~N}$ (nadir-viewing) and $3 \mathrm{~B}$ (backward-viewing) of an ASTER Level-1A image acquired in the Visible Near Infrared (VNIR). The VNIR subsystem of ASTER includes two independent telescopes that facilitate the generation of stereoscopic data. There is a time lag of approximately one minute between the acquisition of the nadir and backward images. Starting in early summer of 2006, LP DAAC has implemented a new production software for efficiently creating quality DEMs starting from the ASTER stereo pairs $[19,20]$. Based on an automated stereocorrelation method, the new software generates a relative DEM without any ground control points (GCPs). It utilizes the ephemeris and altitude data derived from both the ASTER instrument and the Terra spacecraft platform. The ASTER DEM is a single-band product with 30 -meters 


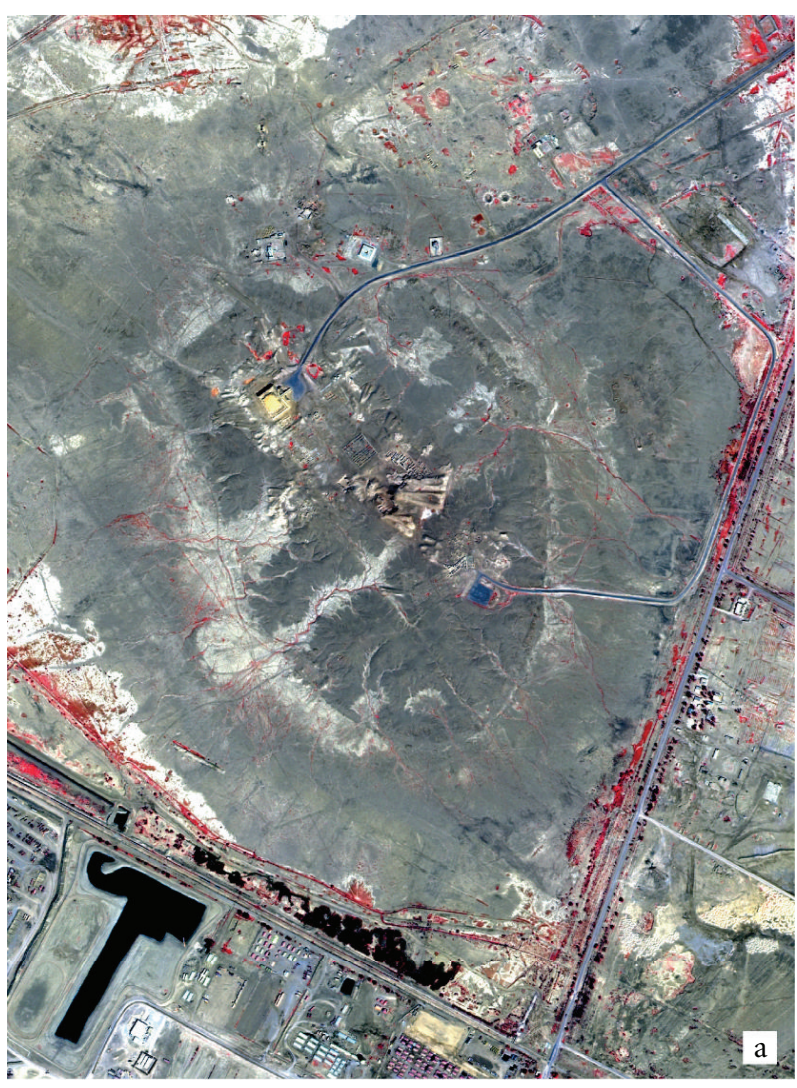

(a)

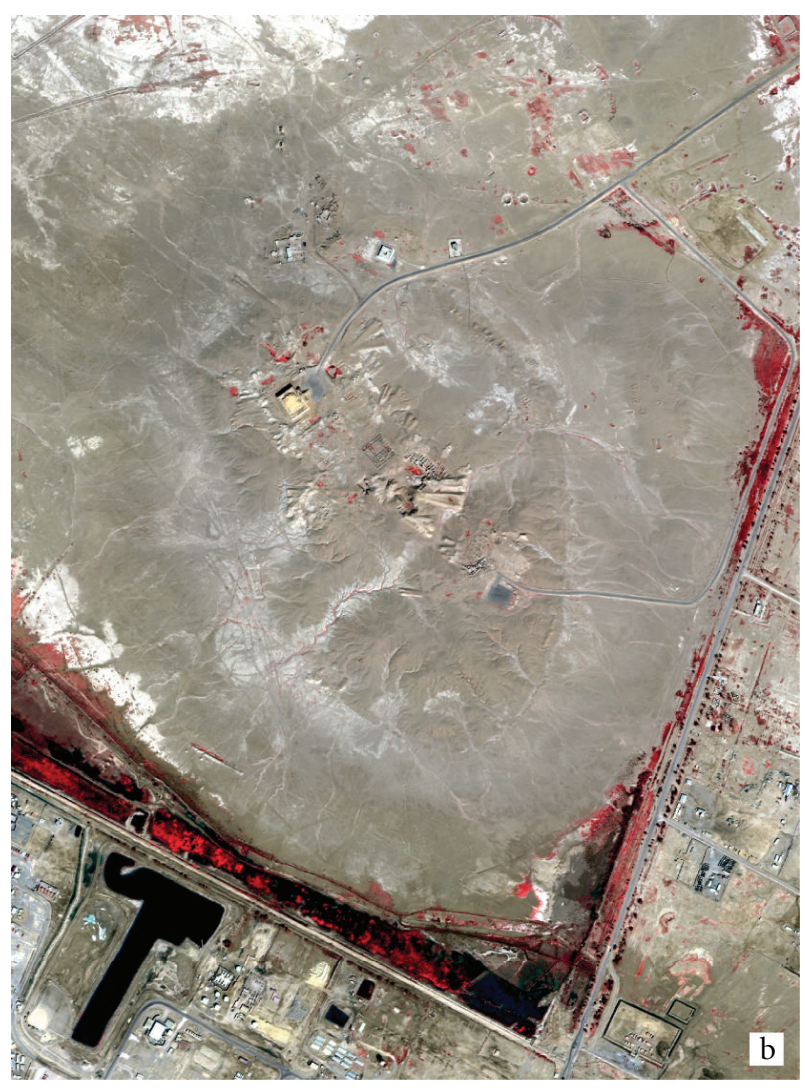

(b)

FIGURE 6: Ur in a pan-sharpened QuickBird-2 image of April 2004 (colour composite RGB bands 4-3-1) and in a pan-sharpened QuickBird-2 image of March 2007 (colour composite RGB bands 4-3-2).

horizontal postings that is geodetically referenced to the UTM coordinate system and referenced to the Earth's geoid using the EGM96 geopotential model.

Both the ASTER DEM and the SRTM DEM were alternatively used to orthorectify satellite images through the Rational Polynomial Coefficients released by the satellite company: Rational Polynomial satellite sensor models are simpler empirical mathematical models relating image space (line and column position) to latitude, longitude, and surface elevation. The name Rational Polynomial derives from the fact that the model is expressed as the ratio of two cubic polynomial expressions. Actually, a single image involves two such rational polynomials, one for computing line position and one for the column position. The coefficients of these two rational polynomials are computed by the satellite company from the satellite's orbital position and orientation and the rigorous physical sensor model.

The aberrations on the images caused by satellite absolute position at taking time has been reduced (as much as possible in the absence of Ground Control Points) using threedimensional models SRTM and ASTER in association with ortho-rectifying algorithms implemented in software like ENVI or PCI Geomatica. So it was possible to upgrade the archaeological plan of the site and to create an up-to-date vector documentation.

Once georeferenced and geometrically corrected, image processing was carried out on some satellite images, panchromatic and multispectral, acquired from Ikonos-2 and QuickBird-2 platforms. In particular, work was oriented in two directions: on the one side, we proceeded to elaborate the multispectral bands and to produce high-resolution colour images from the fusion with panchromatic images through various algorithms of pan-sharpening; on the other side, the georeferencing and orthorectification of panchromatic images for cartographic purposes were carried out. The multispectral processing of the images and the subsequent analysis of data from the near infrared and from the bands of the visible spectrum, was taken up in successive steps: the first phase of the work is consisted in the fusion of the different bands forming the data set of a raw satellite image. In fact the sensors of commercial satellites QuickBird2 and Ikonos- 2 acquire at the same time the same image in two different geometric resolutions: the panchromatic ones can reach a resolution at nadir of about 0.60 and $0.80 \mathrm{~m}$, while the multispectral ones can reach a resolution between 2.40 and $3.20 \mathrm{~m}$. The acquisition in multispectral mode for this type of satellites is in turn subdivided in four bands of the spectrum: red, green, blue (bands of the spectrum visible to the naked eye), and near infra-red (NIR-spectrum invisible to the naked eye). The images with different geometric resolution do not allow their direct overlay, unless an appropriate breakdown of the pixels is carried out, and a resampling through several algorithms: the most performance for images analysis aimed to the archaeological 


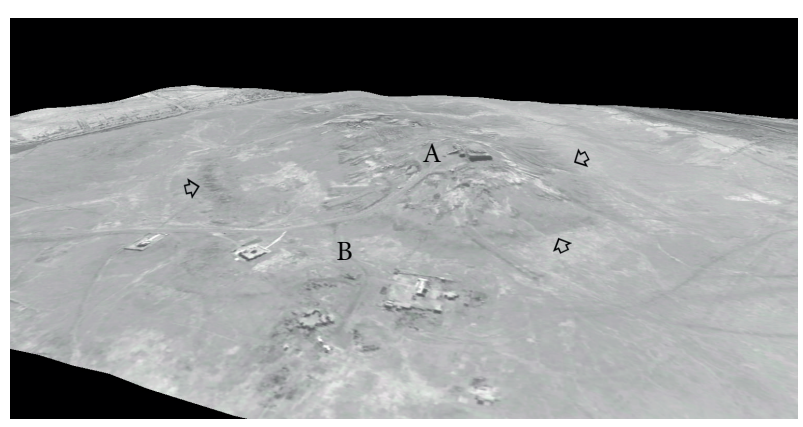

Figure 7: The QuickBird-2 panchromatic image of April 2004 draped on the DEM based on SRTM data: a view from the north, with the Ziggurat on the top of the hill (A), and the North Harbour area (B); the arrows indicate traces and remains of the city walls.

research were those of Zhang, implemented in the PCI Geomatica software, and the Gram-Schmiedt algorithm, implemented in ENVI [21]. Using these algorithms it is possible to obtain high-resolution images (between 0.70 and $1 \mathrm{~m}$ ) in the four bands acquired by QuickBird-2 and Ikonos-2 sensors (Figure 6; see also Figures 10-11 and 13).

The orderly overlaying of the single bands thus allows to visualize the image in true colours or in false colours, highlighting each time the different types of anomalies: for example, the use of red and near infra-red bands resulted being the most suitable to spot the anomalies and traces that are an outcome of vegetation growth. In fact, in the visible spectrum the red wavelength is very sensitive to the energy absorbed by chlorophyll during photosynthesis, while in the near infra-red the energy released by the internal structure of the leaves is highlighted. These data were also analyzed by dedicated software like PCI Geomatica 10.0 and ENVI 4.7 that implements algorithms for image enhancement like for example, the NDVI, useful for analyzing the growth rate, of vegetation in a defined area [22]; these are interpreted in order to acquire new data on the potential presence of buried structures that have affected vegetation growth.

The availability of modern satellite images with high geometric resolution represents a tool with enormous potential for the study of ancient urban and territorial contexts. These images provide plan views and, together with the photos of the 1960s spy satellites, make a complete multitemporal documentation of the archaeological areas. The manual vectorization of all archaeological remains and traces visible in the multi-temporal remote sensing data so allowed the creation of a new archaeological map (see Figure 2), ready for input in a GIS, with new data on the ancient topography of the site, monuments, and roads; in the map, the contour lines were extracted from the DEM based on SRTM and ASTER data. In addition, the three-dimensional models were used, together with QuickBird-2 panchromatic image of April 2004 , to create a realistic 3D image of the ancient area, as it now appears (Figure 7).

\section{Ancient Topography of the Site and Monitoring of the Archaeological Area}

The processing and visual analysis of all acquired photos and satellite images available were very important for the study of Ur due to the inaccessibility of the archaeological area for scholars and the unavailability of vertical aerial photos and cartographies. This remote-sensed documentation allowed the acquisition of new data about the topographical layout of the city and its monuments, the ancient road network, and the paleoenvironmental context; these data are critical for the reconstruction of the historic landscape in which the settlement was located. In fact, a lot of traces and anomalies linked to archaeological and paleoenvironmental features were identified $[1,2]$. In particular, the satellite images taken in winter and early spring, as most of those used in this study, are very useful for the visual photo-interpretation; in fact in these periods the more humid climate allows some types of traces (crop marks and damp marks) to be better visible, while in southern Iraq summer and early autumn are too dry and the archaeological traces are scarce clear. Furthermore, the draping of satellite images on DEMs (together with the only oblique image and in which the scarce air-photo available) highlighted the anomalies due to microrelief and allowed to connect the traces with the morphology of the site.

The integration of the documentation from old excavations and the remote-sensed data allowed the update of the archaeological map of Ur (see Figure 2), where all ancient remains and traces visible in the satellite images (orthorectified using the SRTM DEM and the Rational Polynomial Coefficients) were georeferenced. From the new digital archaeological map of Ur it is also possible to extract diachronic maps that document the historical development of the city during its main phases (Figure 8): (i) the Sumerian period, from the 1st to the 3rd Dynasty; (ii) the Isin and Larsa Dynasties; (iii) the Kassite period; (iv) the Neo-Babylonian age.

First of all, satellite images provide plan views of the entire archaeological area of Ur, very useful for a site where excavations were focused only on single monumental complexes or buildings and in which the studies had not interested the general layout of the settlement; they make available a complete image of the site, where different monuments and archaeological areas are together integrated and correctly localized. So, it is possible to understand the mutual relationships between various sectors of the urban area and different buildings.

In particular, it is possible to see the whole perimeter of the city with its circuit of walls and the position, plan, and reciprocal relationships of the buildings that were excavated between 1919 and 1934 (see Figure 3). In the highest part of the tell, the sacred area with the Ziggurat and the other main monuments are visible, while at the northern end and in the south-eastern part of the city it is possible to distinguish the depressions corresponding to the two harbours, today silted up. It is important also to note the presence of another depression stretching southwards from the northern harbour and passing to the east of the sacred area; it then curves towards the south-west, terminating 


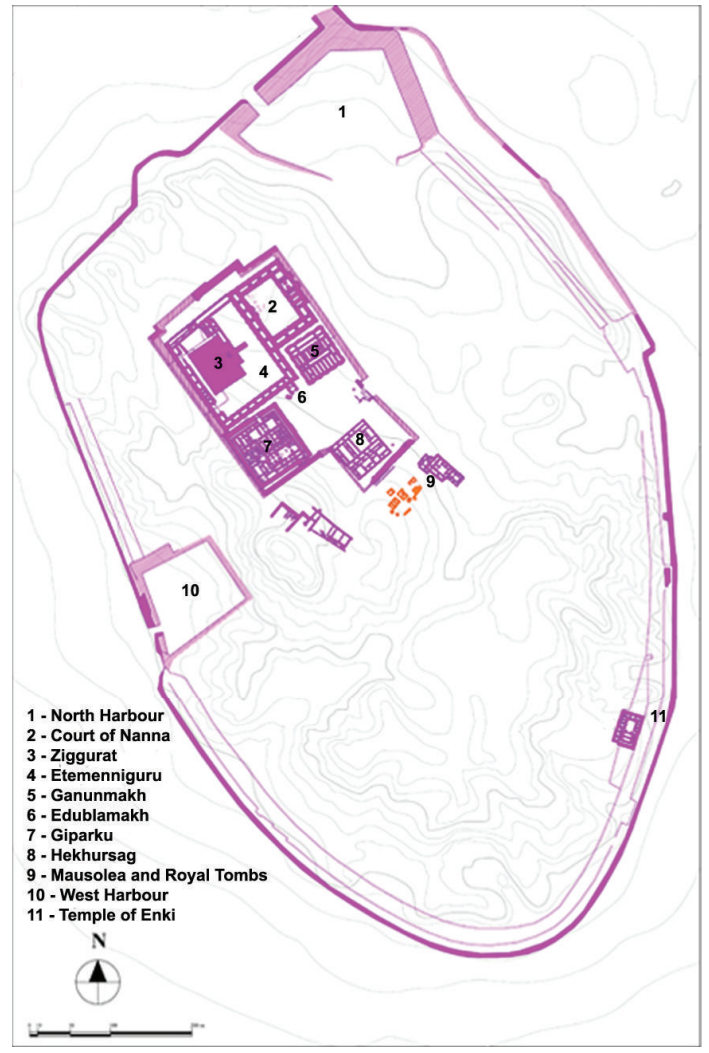

(a)

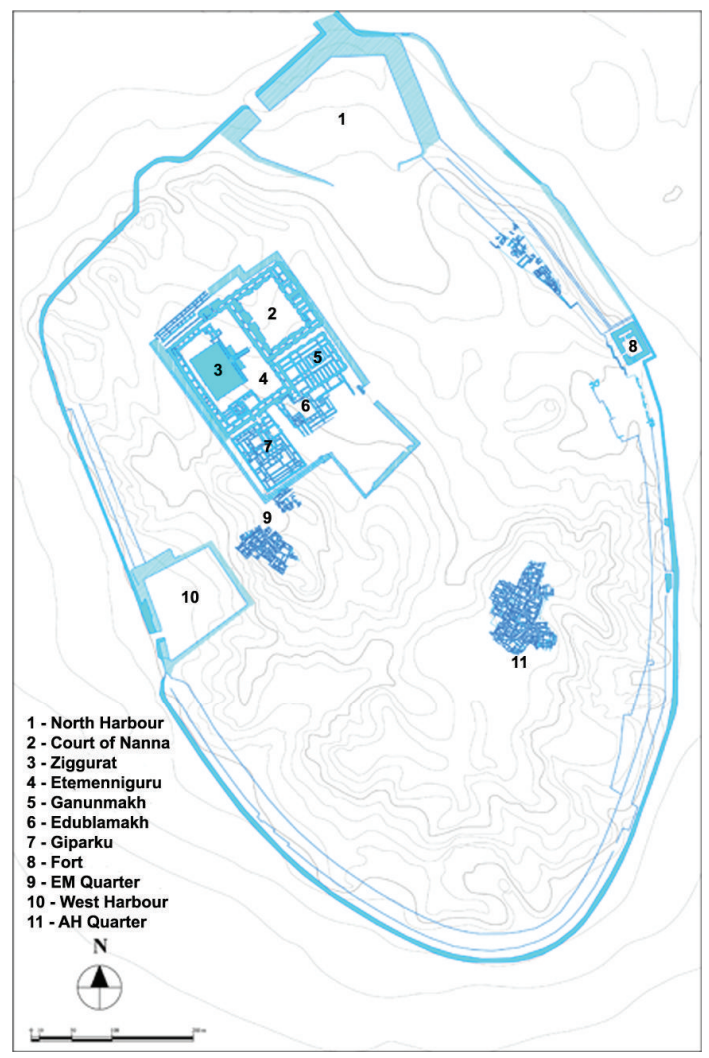

(c)

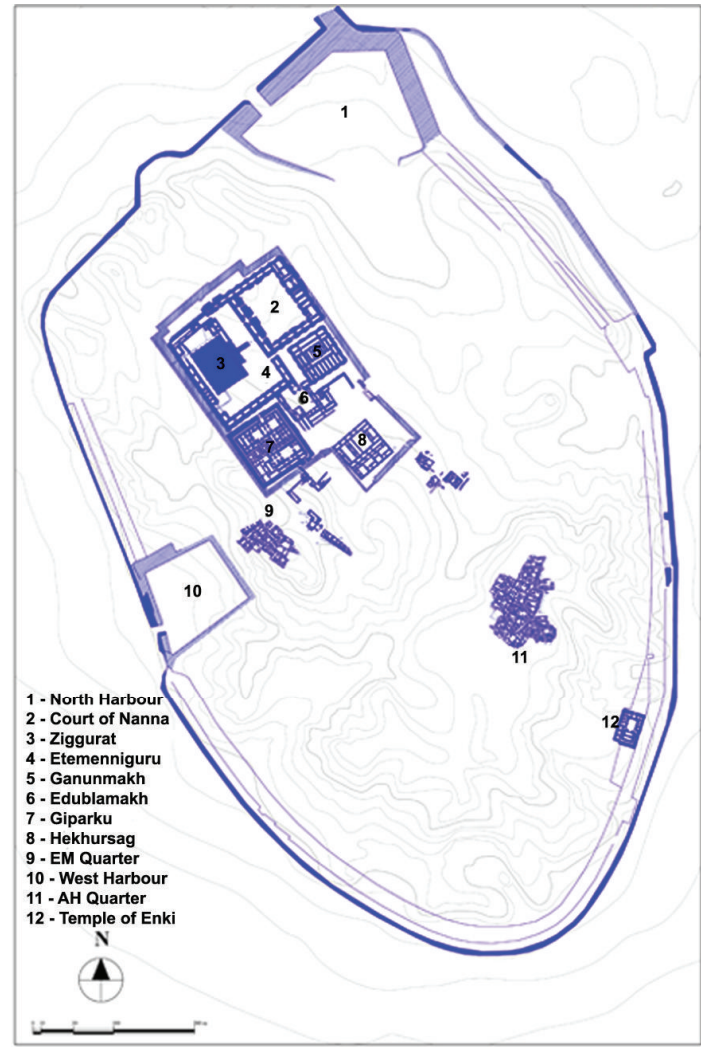

(b)

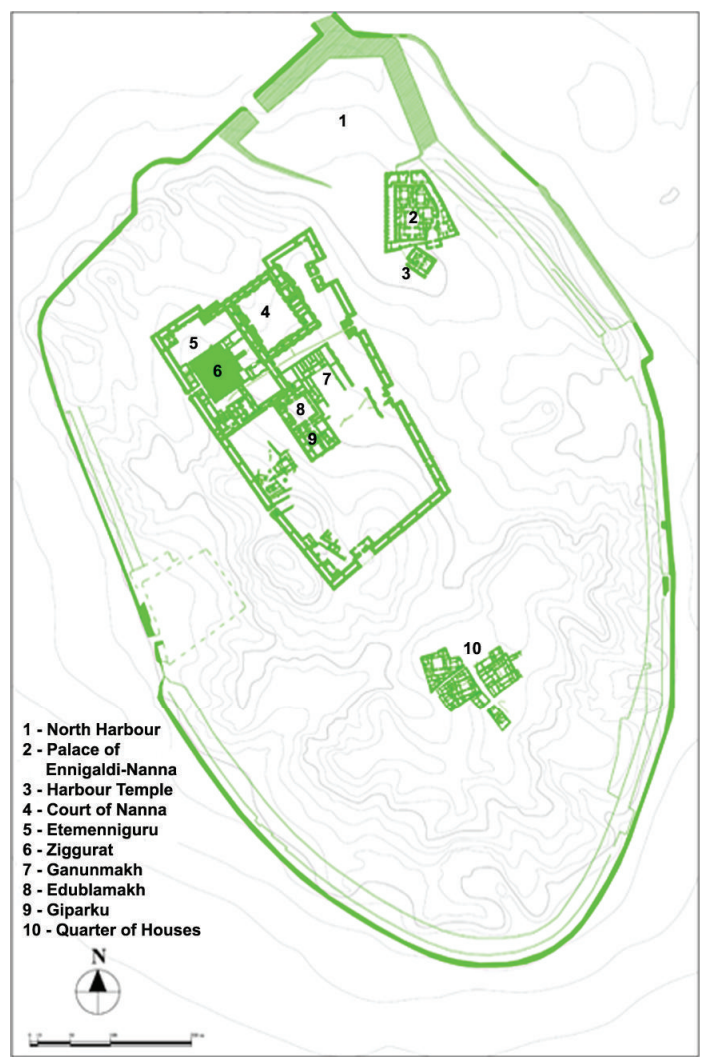

(d)

Figure 8: Maps of the main phases of Ur: (a) the Sumerian period, from the 1st to the 3rd Dynasty; (b) the Isin and Larsa Dynasties; (c) the Kassite period; (d) the Neo-Babylonian age. 


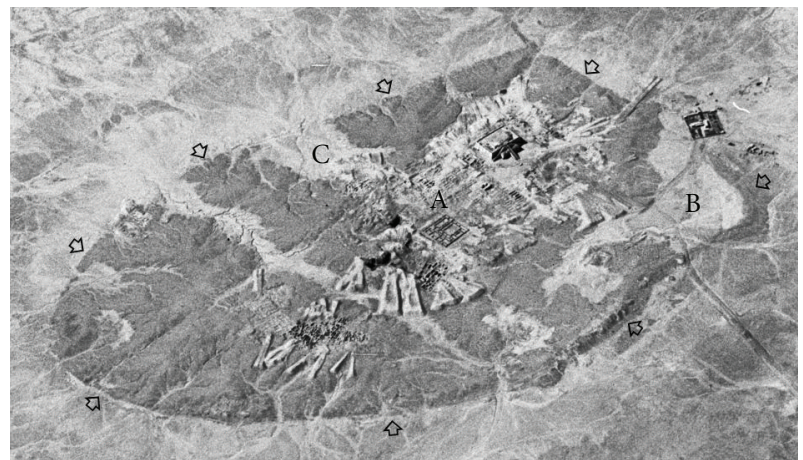

Figure 9: An oblique view of Tell al Muqayyar (Ur) in a Gambit KH-7 photograph acquired in February 1966: A: the sacred area on the top of the hill; B: the North Harbour; C: the West Harbour. The arrows indicate traces and remains of the city walls.

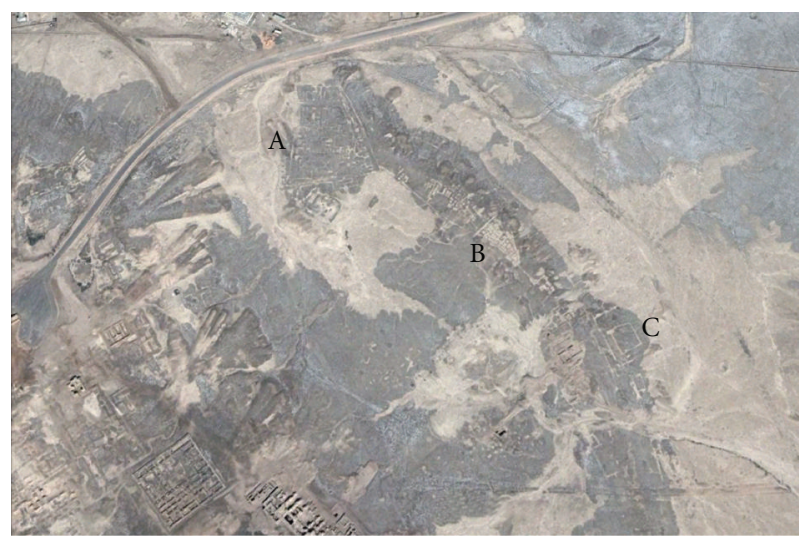

Figure 10: Traces and remains of the Palace of Ennigaldi-Nanna (A), of few houses built against the city walls (B), and of the Kassite Fort (C) in a pan-sharpened QuickBird-2 image of February 2002 (colour composite RGB bands 3-2-1).

to the south of the south-western harbour: this depression probably corresponds to the channel that crossed the city from the northern harbour and which was built or restored by Hammurabi. The remains and traces of the defensive city walls were also well visible in a Gambit $\mathrm{KH}-7$ oblique photo of February 1966 (Figure 9) that shows very well the morphology of the site.

In the Northern part of the urban area, the satellite images show in detail the depression corresponding to the main harbour of Ur, which, besides being buried, is also partially covered by some modern constructions; particularly in the Gambit KH-7 vertical photo of April 1966, it is even possible to make out a few traces of the inner edge of the northern and south-western docks. Further south may be seen the remains and traces of the Palace of Ennigaldi-Nanna, today partly reburied after its excavation (Figure 10). The scant remains of the so-called Harbour Temple are visible immediately to the south. In the north-eastern sector of Ur, the satellite images show quite clearly the traces of the

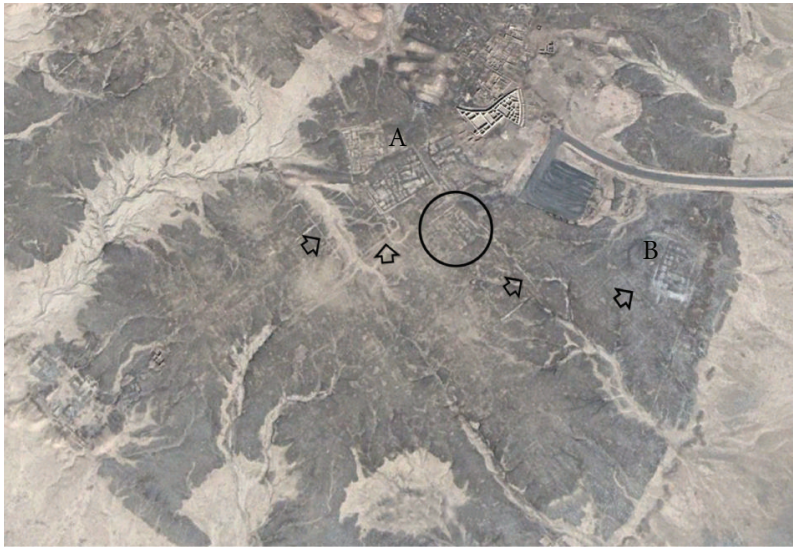

FIgure 11: Traces of structures and streets between the NeoBabylonian Houses (A) and the Enki Temple (B) in a pan-sharpened QuickBird-2 image of February 2002 (colour composite RGB bands 3-2-1): the arrows indicate buried streets and walls along their sides, while the circle highlights buried structures (maybe other NeoBabylonian houses).

fortifications, only partially excavated. Also visible are the scant remains and traces of a few houses built against the walls and of the quadrangular Kassite Fort, which stood in this stretch of the fortifications.

In the south-eastern sector of the city, satellite images clearly show the path of the walls; the scarce traces of the small Temple of Enki and the remains of the so-called $\mathrm{AH}$ Quarter are visible nearby (Figure 11). The last residential complex dates back to the period of the Isin and Larsa dynasties; the view from above shows the plan of the restored area, with the houses built up against each other and separated by narrow winding streets. Traces of the structures, partly reburied after the excavations, of another residential district, dateable to the Neo-Babylonian period, are visible to the south-west; the houses were inserted in a regular urban layout, marked by broad straight roads. The satellite image makes it possible to identify even traces of buried or semiexposed structures, identifiable with other houses and parallel streets: so, it is possible to integrate the excavation areas, showing how the regular urban planning of the NeoBabylonian period concerned a broad section of the southeastern part of Ur.

In the central sector of the city, it is possible to read the entire plan of the monumental sacred area and verify the preservation of the buildings excavated in 1920s and 1930s. The Ziggurat dominates this area, also thanks to its impressive visual impact, which is made even more evident by the modern restoration; on the other hand, traces of the Etemenniguru are scarce. The remains of the Edublamakh, the Ganunmakh, the Giparku, and the Hekhursag are clearly visible, while only some structures pertaining to the so-called Court of Nanna are preserved. It is possible to observe the structures and the traces of two other excavated monuments, the Temple of Nimin-Tabba and the so-called EM District, a 


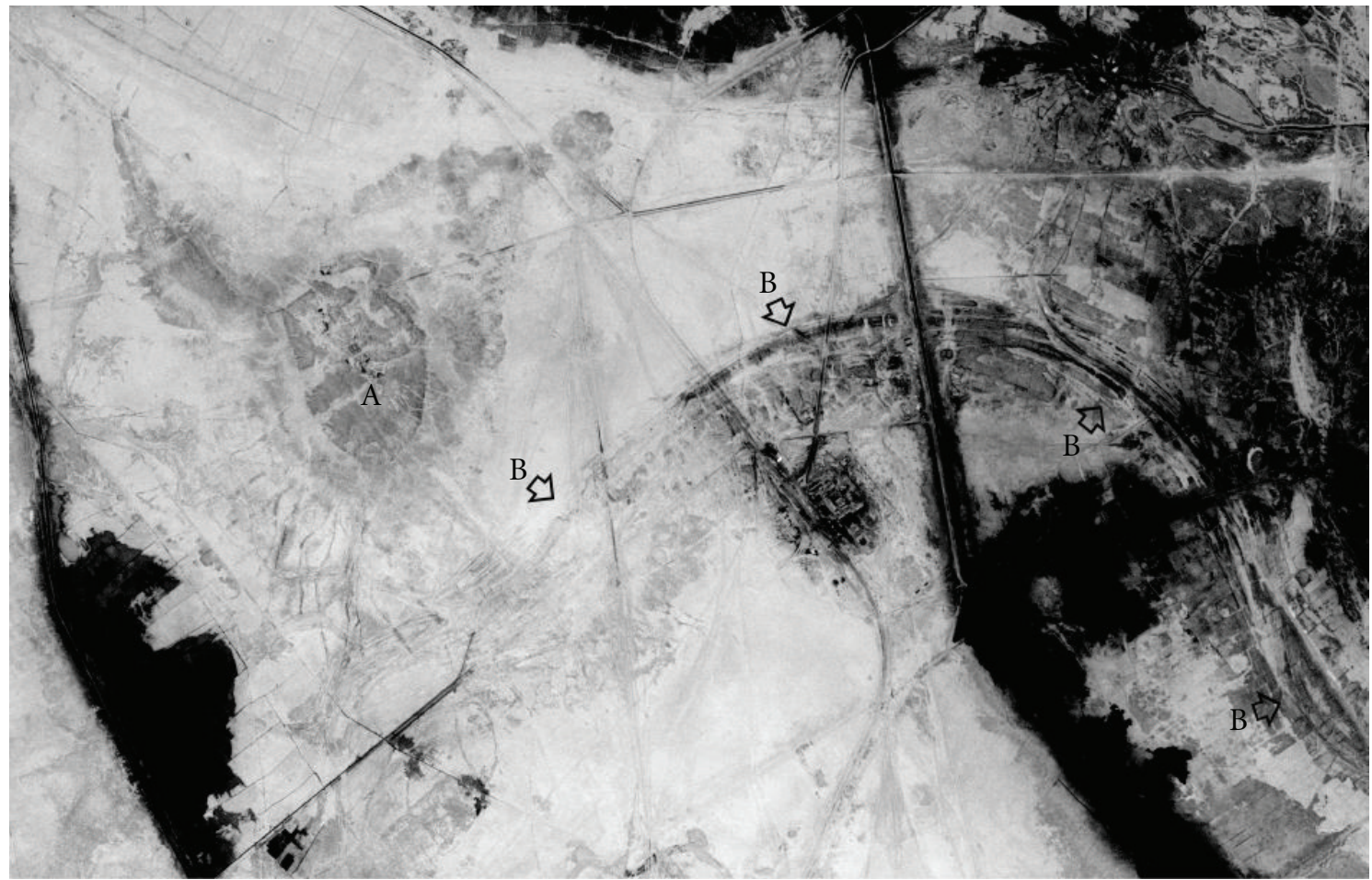

Figure 12: Ur (A) and the surrounding territory in a Corona KH-4B photo of May 1968: a lot of traces (B) of the paleoriver bed of the Euphrates are visible.

residential sector poorly conserved and dateable to the IsinLarsa period. The broad pit resulting from the excavation of the so-called Royal Cemetery Clearly is visible to the south of the Hekhursag; the necropolis is characterized by the presence of numerous burials of high dignitaries and kings of Ur.

The remote-sensed documentation also provided important data concerning the reconstruction of the landscape surrounding Ur, where a lot of traces of old channels and paleoriver beds of the Euphrates were identified in areas much modified and altered during the last decades by urbanization and agricultural works. For this reason, the high-resolution USA reconnaissance photographs taken in 1966 by Gambit KH-7, which document the region of Nasiriyah, are very useful (see also Figure 4). In particular, they show the traces of a paleo-river bed of the Euphrates to the south-west, to the south, and to the south-east of the hill where the city was built; in fact, in ancient times the bed of the river ran near Ur, that, how we have seen, had two harbours and was an important trading centre. So, the Gambit image documents the paleohydrology of the area, in a territory that today is partially modified and altered by modern structures and above all by the military base and the airport built about $500 \mathrm{~m}$ south-west of the ancient city, exactly over the paleoriver bed, which was visible also in the Corona KH-4B image of 1968 (Figures 12 and 13). The oblique Gambit KH-7 photo, taken from the east in 1966, shows the modern route of the Euphrates, very far from the ancient city (Figure 14).

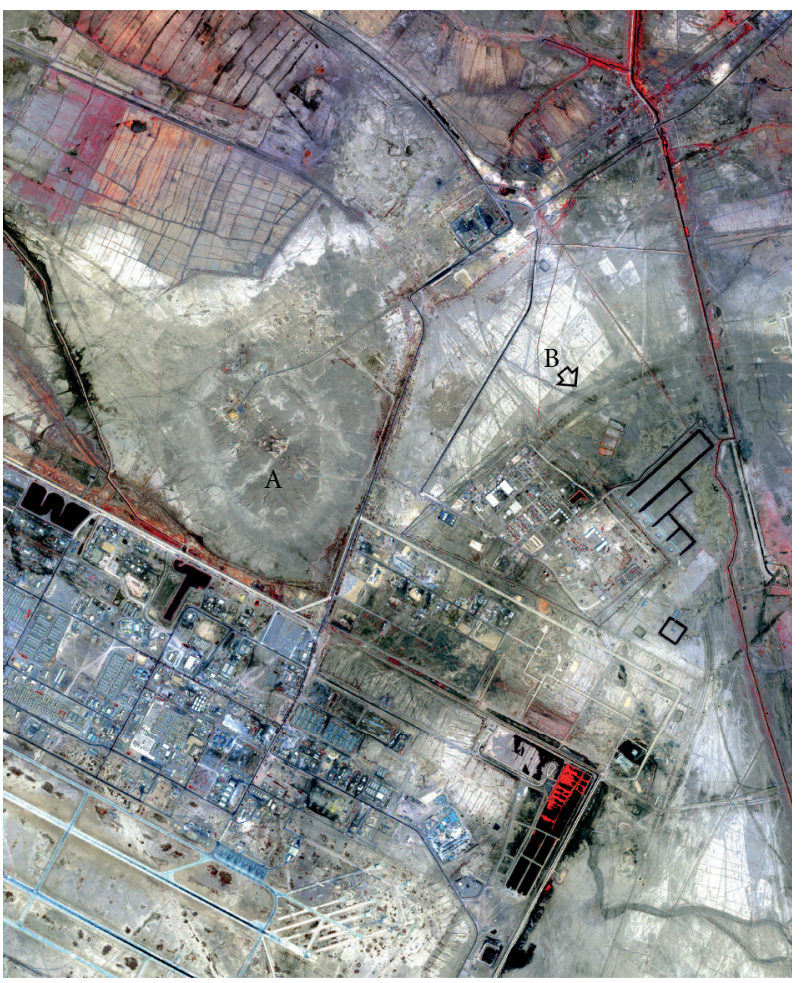

FIGURE 13: Ur (A) and the surrounding territory in a pan-sharpened Ikonos-2 image of 2008 (colour composite RGB bands 4-3-2): only some traces (B) of the paleo river bed of the Euphrates are visible. 


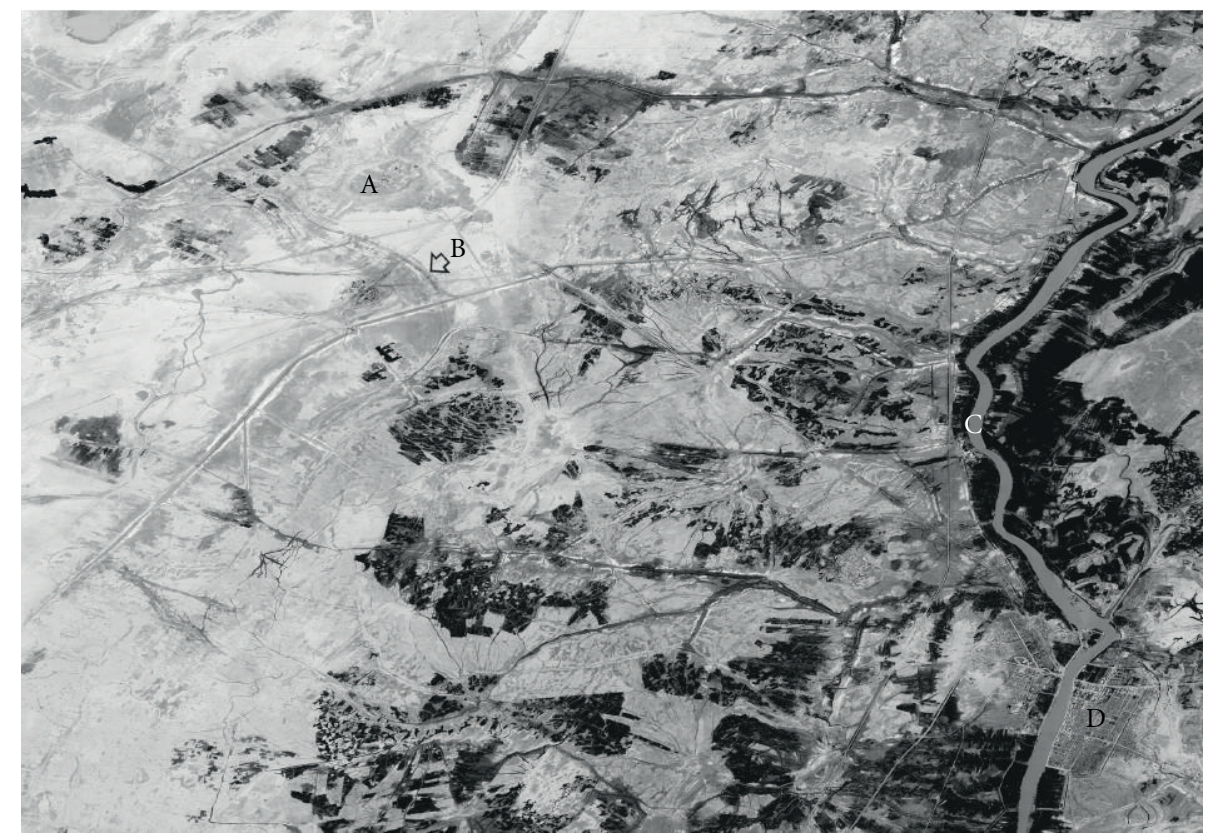

FIGURE 14: Gambit KH-7 oblique photo of 1966: A: Ur; B: paleo river bed of the Euphrates; C: present river bed of the Euphrates; D: Nasiriyah.

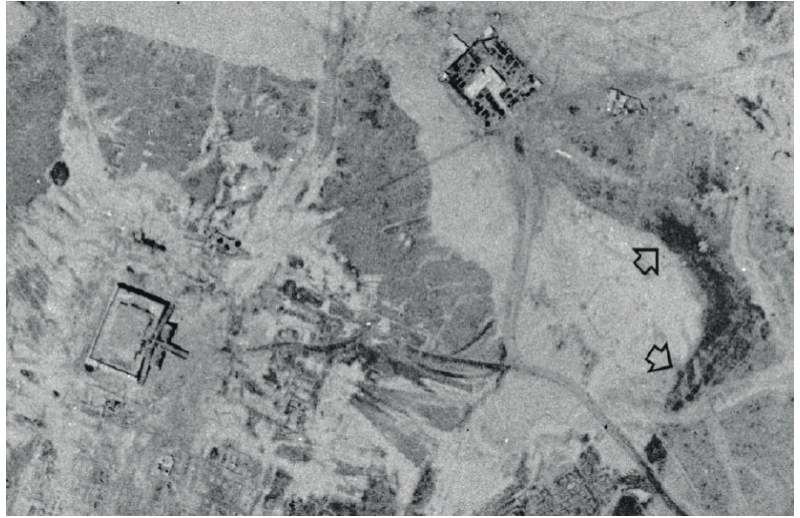

(a)

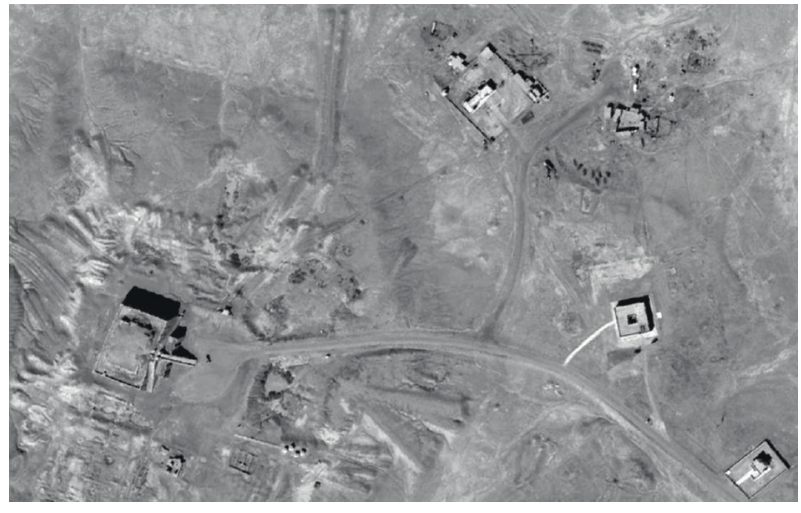

(b)

Figure 15: The area of the North Harbour in a Gambit KH-7 photo of 1966 (a) and in the WorldView-1 image of 2008 (b): the arrows show the traces and remains of the northern and north-eastern docks.

Lastly, the multitemporal satellite images allowed the monitoring of the conservation of archaeological area during the last four decades and particularly before and after second Gulf War. In fact, in time of war, satellite images provided a crucial and invaluable tool for monitoring archaeological sites as well as their preservation or fdamage. Moreover, for a documentation of the situation before the first Gulf War and to study the area in a period chronological nearer the times of the archaeological excavations, the photos taken from the United States reconnaissance satellites are very useful. For example, the comparison between the vertical Gambit KH-7 image of 1966 and the WorldView-1 image of 2008 shows that during the 1960s some buildings and structures excavated between 1919 and 1934 were better preserved than today (see Figure 3): the Palace of Ennigaldi-Nanna and the nearby residence of the high priestess of Nanna/Sin, the quadrangular Kassite fortress, the so-called AH Quarter and the North Harbour (Figure 15).

\section{Conclusions}

Through this experience, we could appreciate, one more time, the usefulness of historical and recent satellite images for remote analysis of archaeological sites. The potential of such data in research studies becomes even more evident when one considers that the revisit time of the last built satellites has further lowered: this feature allows not only to 
acquire information programming also the time of taking the image (useful for example to analyze the shadows and calculate the height above ground of archaeological evidence) but also to implement systems for remote monitoring of archaeological sites. The completeness of the data set available for the study of Ur also made it possible not only to create an archaeological map in which all the evidence brought to light by the excavations and the visible traces are displayed in their correct relation to each other but also to contextualize the surrounding area, also reconstructed by using old satellite images. The analysis of historical and recent images, together with the availability of altimetric data acquired by SRTM mission and ASTER images, has helped to achieve a much more accurate and precise classification of the entire archaeological area, as well as to simplify the presentation of data, which are now easily understandable to nonspecialists, who may visit the site of the Virtual Museum of Iraq (http://www.virtualmuseumiraq.cnr.it/), while for a viewing of the maps created ad hoc for three other ancient centers of Iraq (Hatra, Khorsabad, and Seleucia), they can see the "Ancient cities of Mesopotamia" webGIS [7].

\section{Acknowledgments}

The "Virtual Museum of Iraq" Project was coordinated by Dr. Massimo Cultraro of the CNR-IBAM. The work concerning the satellite remote-sensed data was carried out by Drs. Laura Castrianni, Imma Ditaranto, Fabrizio Ghio, Giuseppe Pellino, Ilaria Miccoli, and Veronica Randino in the Ancient Topography, Archaeology and Remote Sensing Laboratory of the CNR-IBAM. The work concerning the $3 \mathrm{D}$ reconstruction was directed by Dr. Francesco Gabellone and carried out by Ivan Ferrari, Francesco Giuri, and Massimo Limoncelli in the Information Technologies Laboratory of the CNR-IBAM. The present work was made in strict cooperation between the authors; Sections 1,2, and 5 are written by Giuseppe Scardozzi, while Giacomo Di Giacomo is the author of Sections 3, 4, and 6 .

\section{References}

[1] F. Gabellone and G. Scardozzi, "Integrated technologies for the reconstructive study of Mesopotamian cultural heritage: the cases of Ur, Uruk and Nimrud," in Proceedings of the International Congress on Cultural Heritage and New Technologies, Workshop 11"Archäologie und Computer", pp. 1-46, Vienna, Austria, October 2006.

[2] F. Gabellone and G. Scardozzi, "From the object to the territory: image-based technologies and remote sensing for the reconstruction of ancient contexts," Archeologia e Calcolatori, supplement 1, pp. 123-142, 2007.

[3] M. Cultraro, F. Gabellone, and G. Scardozzi, "Integrated methodologies and technologies for the reconstructive study of Dur-Sharrukin (Iraq)," in Proceedings of the 21st International Symposium on AntiCIPAting the Future of the Cultural Past (CIPA '07), vol. 1, pp. 253-258, Athens, Greece, 2007.

[4] M. Cultraro, F. Gabellone, and G. Scardozzi, "From remote sensing to $3 \mathrm{D}$ modelling and virtual reconstructions of the Iraqi archaeological sites: the case of Hatra," in Proceedings of the 1st International Workshop on Remote Sensing for Archaeology and Cultural Heritage Management, R. Lasaponara and N. Masini, Eds., pp. 239-242, Rome, Italy, 2008.

[5] M. Cultraro, F. Gabellone, and G. Scardozzi, "The virtual musealization of archaeological sites: between documentation and communication," in Proceedings of the Workshop on 3D Virtual Reconstruction and Visualization of Complex Architectures, pp. 1-6, Trento, Italy, February 2009.

[6] M. Cultraro, F. Gabellone, and G. Scardozzi, “The virtual musealization of archaeological sites: between documentation and communication," in Proceedings of 14th International Congress on Cultural Heritage and New Technologies, pp. 294308, Vienna, Austria, November 2009.

[7] G. Di Giacomo and G. Scardozzi, "Un webGIS per la conoscenza delle antiche città della Mesopotamia," in Proceedings of the 2nd Congreso Internacional de Arqueología e Informática Gráfica, Patrimonio e Innovación, pp. 135-139, Seville, Spain, 2010.

[8] G. Scardozzi, "Multitemporal satellite high resolution images for the knowledge and the monitoring of the Iraqi archaeological sites: the case of Seleucia on the Tigris," European Journal of Applied Remote Sensing, vol. 45, no. 4, pp. 143-160, 2009.

[9] G. Scardozzi, "Multitemporal satellite images for knowledge of the assyrian capital cities and for monitoring landscape transformations in the upper course of tigris river," International Journal of Geophysics, vol. 2011, Article ID 917306, 17 pages, 2011.

[10] G. Scardozzi, "The contribution of high resolution satellite images to the production of base-maps and cartographies for archaeological research in Turkey and Iraq," in Remote Sensing for Environmental Monitoring, GIS Applications, and Geology IX, vol. 7478 of Proceedings of SPIE, pp. 1-12, Berlin, Germany, September 2009.

[11] G. Scardozzi, "Old high resolution satellite images for landscape archaeology: case studies from Turkey and Iraq," in Remote Sensing for Environmental Monitoring, GIS Applications, and Geology, vol. 7110/03 of Proceedings of SPIE, pp. 114, Cardiff, UK, September 2008.

[12] G. Bitelli and V. A. Girelli, "Metrical use of declassified satellite imagery for an area of archaeological interest in Turkey," Journal of Cultural Heritage, vol. 10, supplement 1, pp. e35e40, 2009.

[13] A. Beck, G. Philip, M. Abdulkarim, and D. Donoghue, "Evaluation of Corona and Ikonos high resolution satellite imagery for archaeological prospection in western Syria," Antiquity, vol. 81, no. 311, pp. 161-175, 2007.

[14] J. Casana and J. Cothren, "Stereo analysis, DEM extraction and orthorectification of CORONA satellite imagery: archaeological applications from the Near East," Antiquity, vol. 82, no. 317, pp. 732-749, 2008.

[15] N. Galiatsatos, D. N. M. Donoghue, and G. Philip, "High resolution elevation data derived from stereoscopic CORONA imagery with minimal ground control: an approach using Ikonos and SRTM data," Photogrammetric Engineering and Remote Sensing, vol. 74, no. 9, pp. 1093-1106, 2008.

[16] M. Jahjah, C. Ulivieri, A. Invernizzi, and R. Parapetti, "Archaeological remote sensing application pre-post war situation of Babylon archaeological site-Iraq," Acta Astronautica, vol. 61, no. 1-6, pp. 121-130, 2007.

[17] R. Goossens, A. De Wulf, J. Bourgeois, W. Gheyle, and T. Willems, "Satellite imagery and archaeology: the example of CORONA in the Altai Mountains," Journal of Archaeological Science, vol. 33, no. 6, pp. 745-755, 2006. 
[18] J. A. Ur, “Sennacherib’s northern Assyrian canals: new insights from satellite imagery and aerial photography," Iraq, vol. 67, pp. 317-345, 2005.

[19] T. Toutin, "Three-dimensional topographic mapping with ASTER stereo data in rugged topography," IEEE Transactions on Geoscience and Remote Sensing, vol. 40, no. 10, pp. 22412247, 2002.

[20] T. Toutin, "ASTER DEMs for geomatic and geoscientific applications: a review," International Journal of Remote Sensing, vol. 29, no. 7, pp. 1855-1875, 2008.

[21] R. Lasaponara and N. Masini, "Pan-sharpening techniques to enhance archaeological marks: an overview," in Satellite Remote Sensing. A New Tool for Archaeology, R. Lasaponara and N. Masini, Eds., pp. 87-109, Springer, 2012.

[22] R. Lasaponara, N. Masini, and “, "Image enhancement, feature extraction and geospatyal analysis in an archaeological perspective," in Satellite Remote Sensing. A New Tool For Archaeology, R. Lasaponara and N. Masini, Eds., pp. 17-63, Springer, 2012. 

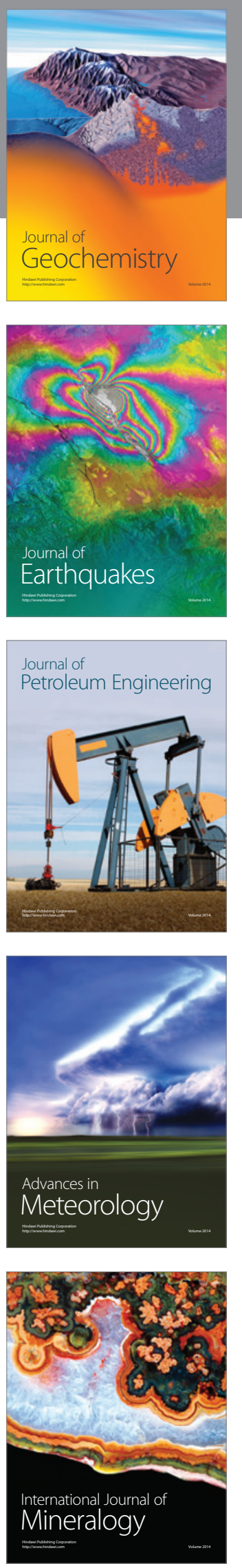
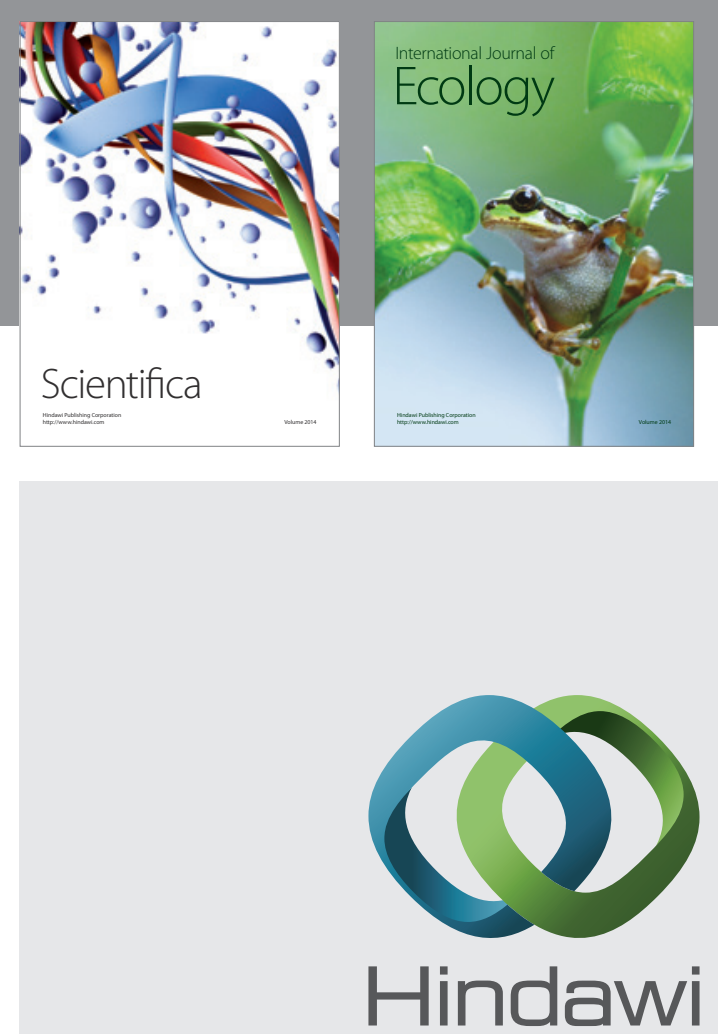

Submit your manuscripts at http://www.hindawi.com
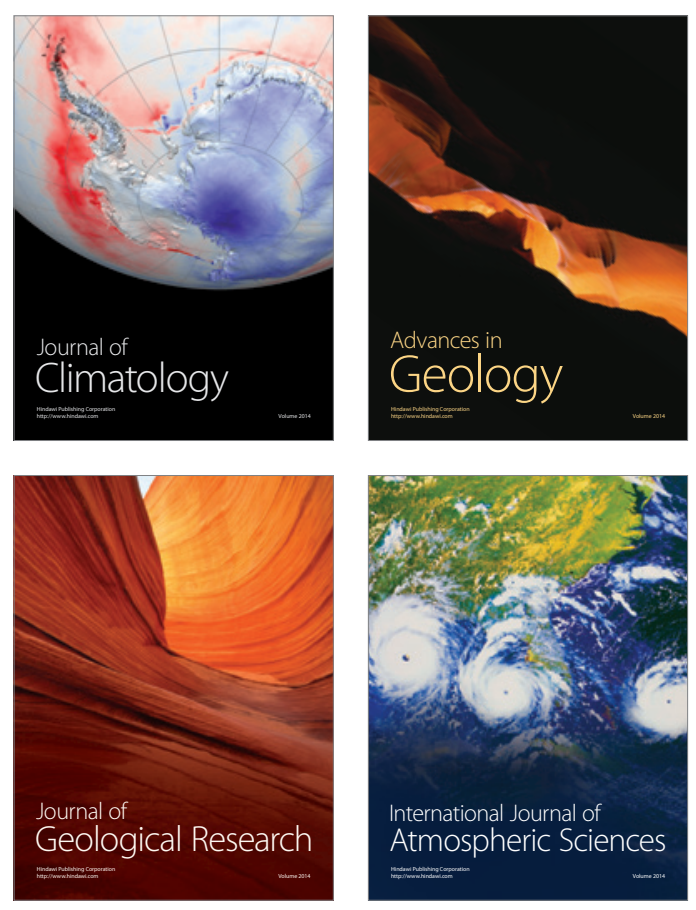
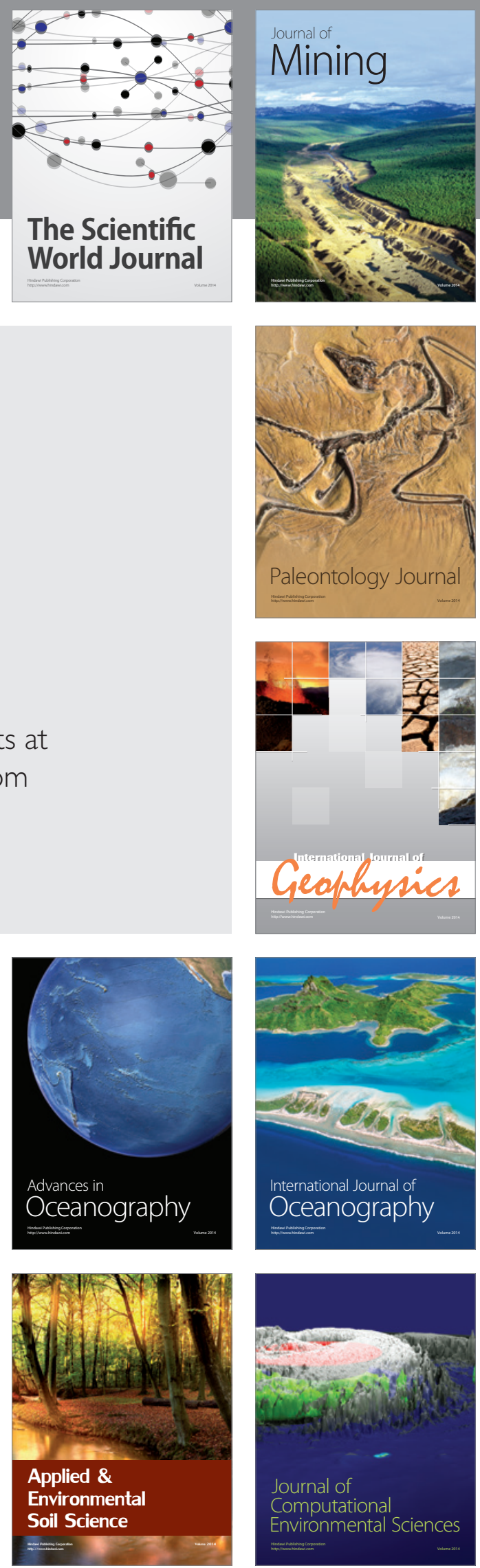